Keywords: Solvent Extraction, Salt Waste Processing Facility, MCU, Next Generation Solvent

Retention: Permanent

\title{
CHEMICAL STABILITY OF POLYPHENYLENE SULFIDE IN THE NEXT GENERATION SOLVENT FOR CAUSTIC-SIDE SOLVENT EXTRACTION
}

\author{
F. F. Fondeur \\ S. D. Fink
}

December 8, 2011

Savannah River National Laboratory Savannah River Nuclear Solutions Aiken, SC 29808

Prepared for the U.S. Department of Energy under contract number DE-AC09-08SR22470.

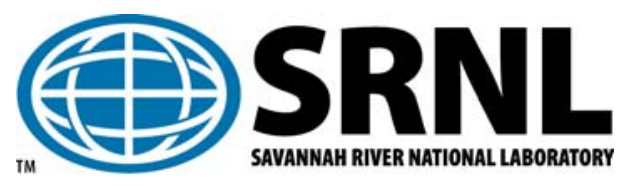


SRNL-STI-2011-00738

Rev. 0

\section{DISCLAIMER}

This work was prepared under an agreement with and funded by the U.S. Government. Neither the U.S. Government or its employees, nor any of its contractors, subcontractors or their employees, makes any express or implied:

1. warranty or assumes any legal liability for the accuracy, completeness, or for the use or results of such use of any information, product, or process disclosed; or

2. representation that such use or results of such use would not infringe privately owned rights; or

3. endorsement or recommendation of any specifically identified commercial product, process, or service.

Any views and opinions of authors expressed in this work do not necessarily state or reflect those of the United States Government, or its contractors, or subcontractors.

\section{Printed in the United States of America \\ Prepared for \\ U.S. Department of Energy}




\section{REVIEWS AND APPROVALS}

AUTHORS:

F. F. Fondeur, Separations \& Actinide Science Programs

Date

TECHNICAL REVIEW:

T. E. Skidmore, Materials NDE and Consultation

Date

APPROVAL:

S. D. Fink, Manager

Date

Separations \& Actinide Science Programs

S. L. Marra, Manager

Date

Environmental \& Chemical Process Technology Research Programs

B.A. Oard, Manager

Date

MCU Life Extension/NGS 


\section{EXECUTIVE SUMMARY}

The Office of Waste Processing, within the Office of Technology Innovation and Development, is funding the development of an enhanced solvent for deployment at the Savannah River Site for removal of cesium from High Level Waste. For simplicity, this solvent is referred to as the Next Generation Solvent (NGS). The technical effort is collaboration between Oak Ridge National Laboratory (ORNL), Savannah River National Laboratory (SRNL), and Argonne National Laboratory. The initial deployment target envisioned for the technology was within the Modular Caustic-Side Solvent Extraction Unit (MCU). ${ }^{*}$ Deployment of a new chemical within an existing facility requires verification that the chemical components are compatible with the installed equipment. In the instance of a new organic solvent, the primary focus is on compatibility of the solvent with polyphenylene sulfide (PPS), the polymer used in the coalescers within MCU. This report provides the data from exposing PPS polymer to NGS. The test was conducted over a three month period.

PPS is remarkably stable in the presence of the next generation solvent. Testing showed no indication of swelling or significant leaching. Preferential sorption of the Modifier on PPS was observed but the same behavior occurs with the baseline solvent. Therefore, PPS coalescers exposed to the NGS are expected to perform comparably to those in contact with the baseline solvent.

\footnotetext{
* Subsequent to the start of this work, the Department of Energy made a programmatic decision to defer deployment of the NGS in MCU in favor of direct deployment in SWPF. However, the potential exists that NGS may still be deployed in MCU at a later date and prior to SWPF deployment if deemed necessary.
} 


\section{TABLE OF CONTENTS}

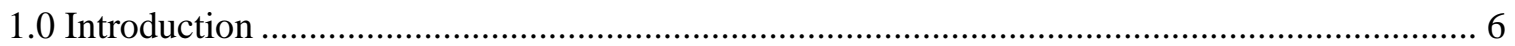

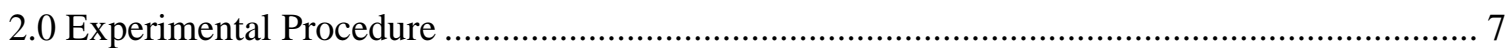

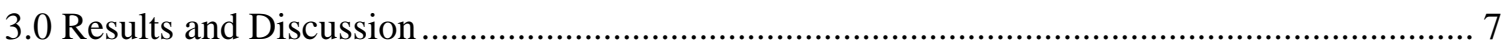

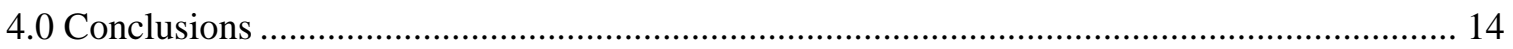

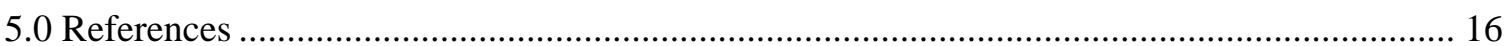




\subsection{Introduction}

Polyphenylene sulfide (PPS) is a semicrystalline polymer with excellent engineering properties and suitable processing temperatures. ${ }^{1}$ PPS can also be made containing branches (using a trifunctional monomer) and with crosslinked microstructure (when curing the monomer at high temperatures in the presence of oxygen).

PPS is made from the condensation reaction between para-dichlorobenzene (1,4-dichlorobenzene or $p$-DCB) and sodium sulfide with the assistance of a catalyst (to lower the activation barrier). The synthesis conditions of PPS have evolved since its invention in the 1960's to the optimal conditions developed by the Philips Corporation in the 1970's. ${ }^{2}$ The resulting polymer consists of chemically stable molecular moieties such as benzene rings and ether like sulfur linkages between the aromatic rings (as shown below).

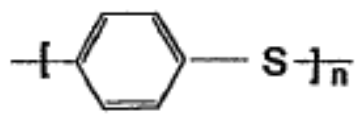

The resulting PPS polymer is a thermoplastic with a sharp melting temperature around $275{ }^{\circ} \mathrm{C}$ that varies (slightly) depending on the polymer processing or aging or storage conditions. The glass transition ranges from 87 (amorphous) to $93{ }^{\circ} \mathrm{C}$ (crystalline) giving this polymer a wide temperature range for processing. This wide temperature range allows for easy processing of this polymer into different (molded) shapes and figures. The molecule is relatively stiff such that upon cooling from the melt this polymer has the tendency to readily crystallize. To minimize crystallization at a practical cooling rate, small amounts of additives (or trifunctional monomers) are added to screen the interchain interactions. A common additive is diphenyl disulfide.

Combinations of quenching rate, temperature, and aging at temperature allows the polymer to have a controlled degree of crystallinity that in turn "tunes in" the bulk mechanical properties of this polymer. Annealing post quenched PPS reduces residual stresses (from quenching) and nucleates small lamellas throughout the polymer to give the polymer higher tensile, compressive and bending strength as well as toughness (exhibited as an ability to arrest internal crack propagation). Blending PPS with fillers (i.e., glass or carbon fibers) is another way to improve the strength of the polymer (via an increase in the glass transition of the polymer for example). An excellent review of the mechanical properties of PPS that includes impact strength (toughness), fatigue, viscoelasticity (creep), and tensile/compressive strength was given in Reference $3 .^{3}$

Heating the polymer at high temperatures for short times (less than minutes) in the presence of air introduces crosslinking microstructure into the polymer that can enhance the ultimate tensile and compressive strength. However, heating the polymer beyond $350{ }^{\circ} \mathrm{C}$ in air introduces significant oxidation reactions (as shown in the table below) that can change the polymer mechanical and chemical stability. 
Temperature in air $\left({ }^{\circ} \mathrm{C}\right)$

350

380

\section{Products}

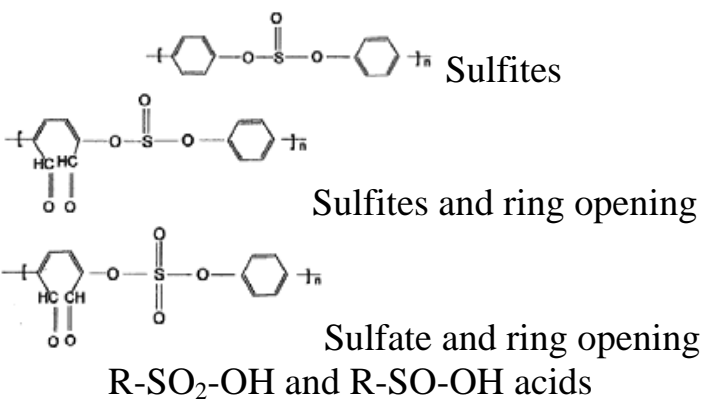

If heating PPS past $300{ }^{\circ} \mathrm{C}$ under a reducing atmosphere, pyrolysis reactions will yield byproducts such as hydrogen, hydrosulfide gases, carbon monoxide, and a carbonaceous residue.

In a previous report, ${ }^{4}$ the stability of PPS in a caustic environment $\left(1.91 \mathrm{M}^{\left.-\mathrm{OH}^{-}\right]}\right)$and under gamma radiation (5 E8 rad at $7 \mathrm{E} 5 \mathrm{rad} / \mathrm{h}$ ) was demonstrated. In addition, that work showed the resistance of PPS to organic liquids such as CSSX present as a secondary phase in caustic and acidic streams used in MCU. Previous reviews in this area (as Reference 3) have not extensively examined the stability of PPS in solutions including organic liquids. In particular, the data is scarce on the effect of blending of organics liquids with different polarities (hydrophobic and hydrophilic) on the dimensional stability of PPS.

In 2010, researchers at ORNL developed an optimized solvent similar to CSSX except that it contains a new extractant (MaxCalix ${ }^{*}$ as an alternate extractant to BobCalixC6 ${ }^{\dagger}$ ) and a new third phase formation preventer or base named $\operatorname{LIX}^{\circledR} 79^{\ddagger}$ (a molecule more basic than trioctylamine, TOA, currently used in CSSX). The new solvent system (associated acronym is NGS) outperforms CSSX (extraction, stripping and minimizes phase carryover) ${ }^{5}$ and it was recently shown to be resistant to gamma irradiation. ${ }^{6}$ However, data on the stability of PPS in NGS are lacking.

The objective of this work was to investigate the chemical resistance of PPS to NGS. The data from this work provides the input necessary for using PPS as the polymer media for both filtration and coalescing oil-in-water dispersion.

\subsection{Experimental Procedure}

The solvent systems investigated are shown in Table 1. The baseline solvent is designated as CSSX, or Caustic-Side Solvent Extraction solvent. As shown in Table 1, the new improved solvent has Modifier ${ }^{f}$ and Isopar $^{\circledR} \mathrm{L}$ as in the baseline solvent but it also includes MaxCalix and guanidine derivative. The latter two new chemicals may alter the interaction of the solvent with PPS.

* 1,3-alt-25,27-bis(3,7-dimethyloctyl-1-oxy)calix[4]arene-benzocrown-6

+ calix[4]arene-bis(tert-octylbenzocrown-6)

${ }^{\ddagger} N, N$-Dicyclohexyl- $N "$-isotridecylguanidine is the active guanidine reagent in LIX $^{\circledR} 79$.

${ }^{f}$ Modifier stands for 1-(2,2,3,3,-Tetrafluoropropoxy)-3-(4-sec-butylphenoxy)-2-propanol, also designated Cs-7SB. 
Table 1. A list and structure of the components that comprise the baseline (CSSX) and the improved solvent (NGS).

Modifier

PPS Exposure to NGS

NGS was prepared with two different concentration levels of LIX ${ }^{\circledR} 79$ (COGNIS) at 3 and $10 \mathrm{mM}$. The $3 \mathrm{mM}$ concentration represents the baseline case while the $10 \mathrm{mM}$ concentration represents conditions caused by evaporation of Isopar ${ }^{\circledR}$ L. Also, the elevated concentration makes LIX ${ }^{\circledR} 79$ detection easier with Fourier-transform Infrared Spectroscopy (FTIR). The Modifier (Cs-7SB), Isopar ${ }^{\circledR} \mathrm{L}$, and MaxCalix where kept at nominal values. Table 2 shows the composition of modified NGS where the LIX ${ }^{\circledR} 79$ concentration was varied as well as the temperature. Table 2 also includes baseline experiments with the CSSX solvent.

The solvents listed in Table 2 were contacted with square coupons (1” x 1” x $3 \mathrm{~mm}$ thick) of nonwoven PPS and then placed in two convection ovens set at 21 and $36{ }^{\circ} \mathrm{C}$. The $36{ }^{\circ} \mathrm{C}$ temperature is the maximum stripping temperature at $\mathrm{MCU}$, while $21^{\circ} \mathrm{C}$ represents ambient temperature or roughly the lowest temperature at which extraction is performed at MCU. ${ }^{*}$ The solvent-PPS samples remained at the specified temperatures for three months after which the PPS was removed from the solvent. The PPS was allowed to drain excess solvent. The spent solvent remained in vials until FTIR analysis was performed.

\footnotetext{
* The lowest allowable operating temperature is $20^{\circ} \mathrm{C}$. However, the experimental temperature control was limited to $21^{\circ} \mathrm{C}$ as the lowest stable condition.
} 
Table 2. The composition of the solvent samples used to determine any chemical interaction between PPS and NGS

\begin{tabular}{|c|c|c|c|c|}
\hline $\begin{array}{c}\text { Sample } \\
\text { Label }\end{array}$ & Temperature $\left({ }^{\circ} \mathrm{C}\right)$ & Max Calix (mM) & Guanidine (mM) & Isopar L/Cs-7SB \\
\hline 76 & 36 & 50 & 3 & $74 \mathrm{wt} \% / 21 \mathrm{wt} \%$ \\
\hline 78 & 21 & 50 & 3 & $74 \mathrm{wt} \% / 21 \mathrm{wt} \%$ \\
\hline 79 & 21 & 50 & 10 & $74 \mathrm{wt} \% / 21 \mathrm{wt} \%$ \\
\hline 80 & 36 & 50 & 10 & $74 \mathrm{wt} \% / 21 \mathrm{wt} \%$ \\
\hline 88 & 36 & 50 & 3 & $74 \mathrm{wt} \% / 21 \mathrm{wt} \%$ \\
\hline 90 & 21 & 50 & 3 & $74 \mathrm{wt} \% / 21 \mathrm{wt} \%$ \\
\hline 91 & 21 & 50 & 10 & $74 \mathrm{wt} \% / 21 \mathrm{wt} \%$ \\
\hline 92 & 36 & 50 & 10 & $74 \mathrm{wt} \% / 21 \mathrm{wt} \%$ \\
\hline 83 & 36 & 0 & 0 & 74 wt \% / 21 wt \% \\
\hline 84 & 21 & 0 & 0 & $74 \mathrm{wt} \% / 21 \mathrm{wt} \%$ \\
\hline 95 & 36 & 0 & 0 & $74 \mathrm{wt} \% / 21 \mathrm{wt} \%$ \\
\hline 96 & 21 & 0 & 0 & $74 \mathrm{wt} \% / 21 \mathrm{wt} \%$ \\
\hline 124 & 21 & \multicolumn{3}{|c|}{ Nominal CSSX Composition } \\
\hline 128 & 36 & \multicolumn{3}{|c|}{ Nominal CSSX Composition } \\
\hline
\end{tabular}

To facilitate interpretation of the FTIR spectra, Fig. 1 provides the peak location that can be used to identify the components of NGS in an FTIR spectrum. Any other peaks seen in an FTIR spectrum of NGS may be due to impurities or interaction peaks (i.e., interactions between components). An interaction peak is typically a shoulder or a derivative peak that remains after performing a subtraction. Interactions (such as hydrogen bonding, acid-base, dipole-dipole or dipole-quadrupolar or induced dipole) between molecular components lead to FTIR peaks shifting position from their position in their original environment. In the case of PPS (which is enriched with aromatic and sulfur molecules that donate back to the aromatic molecules), it is reasonable to expect aromatic enriched molecules like the Modifier to concentrate at the surface of PPS.

\subsection{Results and Discussion}

\section{Solvent Analysis}

With the information provided in Table 2, personnel collected the spent solvent (after contacting PPS for 3 months) and conducted FTIR analysis. Figure 2 shows the FTIR spectra of selective solvent samples from Table 2. A quick glance of Fig. 2 shows the same features in every spectrum making it difficult to detect any differences. To detect differences either chemometrics (partial least squares to extract the remaining unaccounted component) or subtraction is performed. We conducted subtraction since chemometric judging criteria is to minimize variances from a mean spectrum. Figure 3 shows the difference spectra from the samples shown in Fig. 2 after subtracting the Modifier and Isopar $^{\circledR} \mathrm{L}$ spectra (such that the signatures from LIX ${ }^{\circledR}$ 79 and MaxCalix remained for inspection (i.e., looking for depletion or impurities or leachate from PPS). 


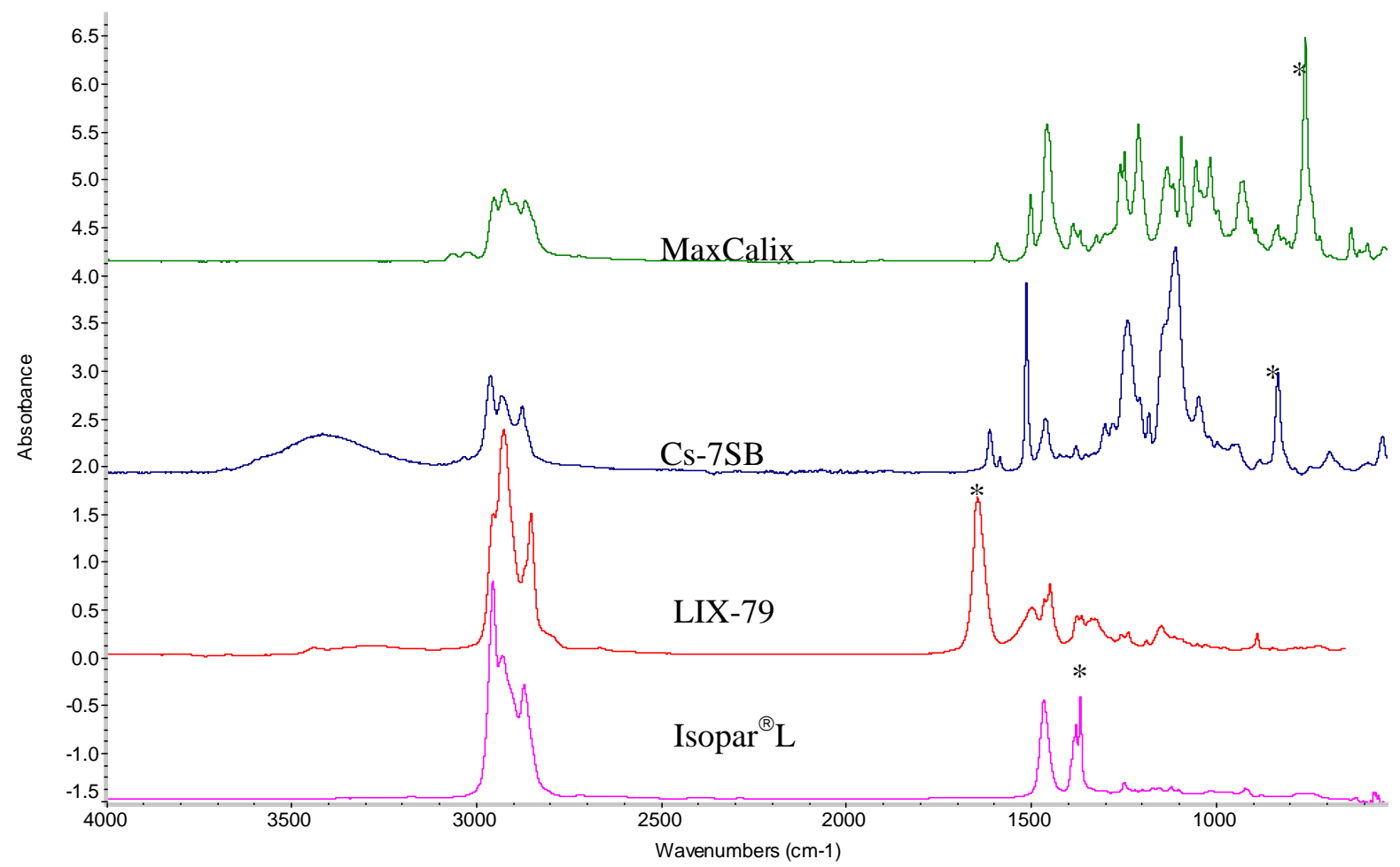

Fig. 1. The FTIR spectra of the pure components that comprise NGS. The asterisks indicate the peak (due to their position and strength) that can be used to identify the components in a spectrum.

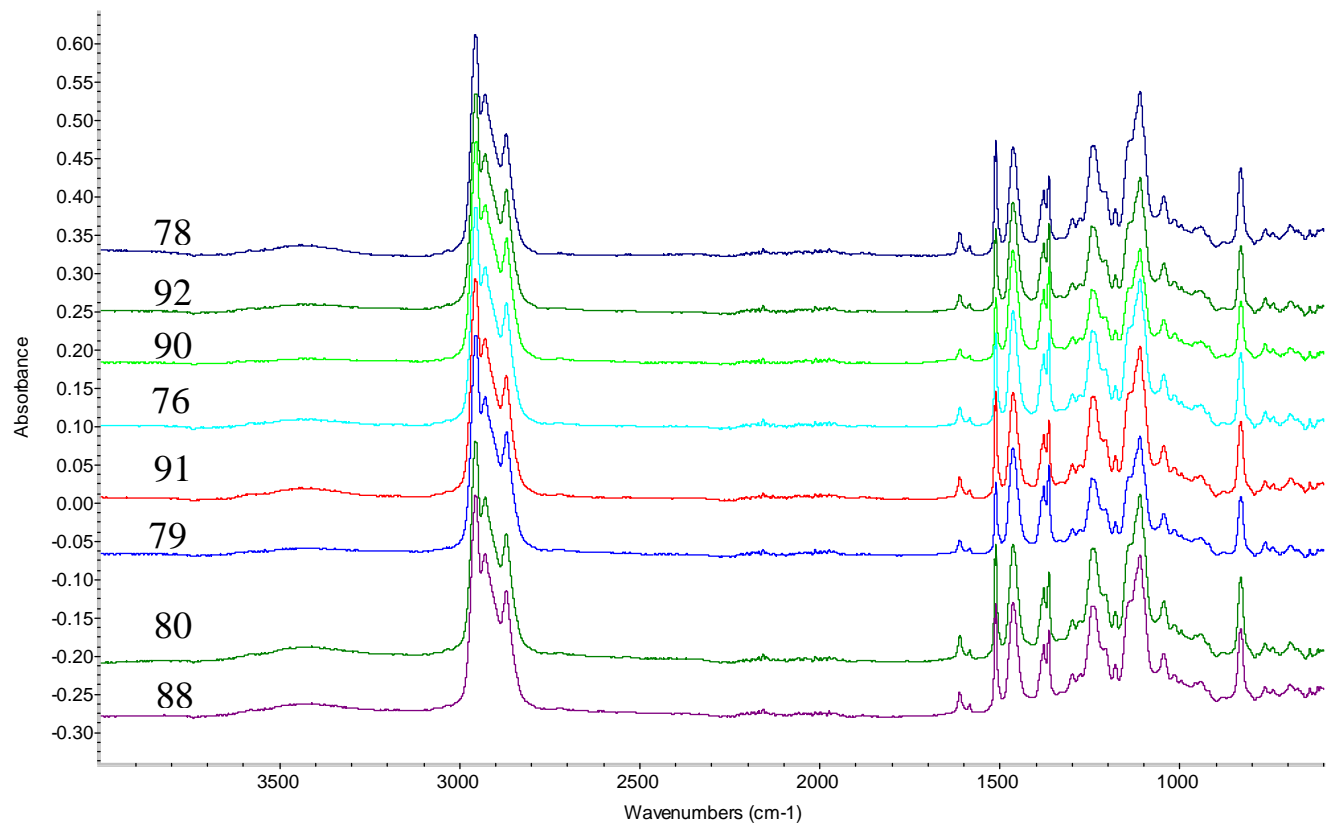

Fig. 2. The FTIR spectra of solvent samples (listed in Table 2) that contacted PPS fibers. 


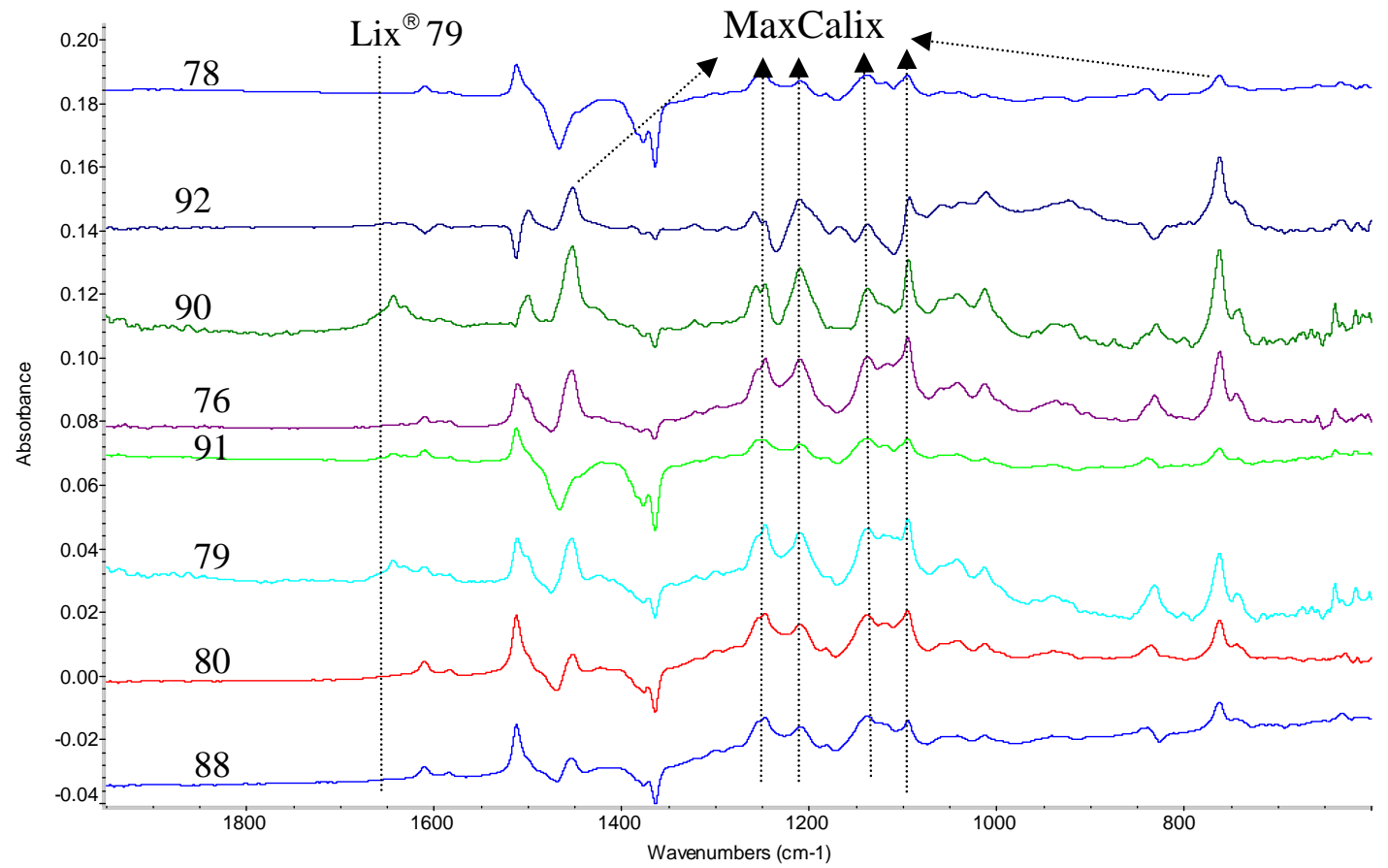

Fig. 3. The difference spectra of solvent samples listed in Table 2 when both the Isopar ${ }^{\circledR} \mathrm{L}$ and Modifier peaks are subtracted.

An inspection of Fig. 3 shows the typical Isopar ${ }^{\circledR}$ L evaporation (Samples 78, 91, 79, 80, and 88). Evaporation in these samples had no correlation with temperature possibly due to sample handling. Fig. 3 also shows that the FTIR was not able to detect LIX ${ }^{\circledR} 79$ at the $3 \mathrm{mM}$ level (i.e., absence of the $1650 \mathrm{~cm}^{-1}$ peak) but readily (although not quantifiable) at the $10 \mathrm{mM}$ level. The signal assigned to LIX $^{\circledR} 79$ is strong in sample 90 where the concentration is $3 \mathrm{mM}$ and this could due to sample handling or sample preparation. Samples 92, 91, and 80 had a low LIX ${ }^{\circledR} 79$ signal indicating that $\operatorname{LIX}^{\circledR} 79$ was below the $10 \mathrm{mM}$ level.

To check the subtraction procedure done in Fig. 3, a similar subtraction was conducted with the spectrum of samples (128 and 124) that were exposed to CSSX at 36 and $21^{\circ} \mathrm{C}$, respectively. Fig. 4 shows the difference spectrum (124 minus 128) where it clearly shows a larger loss of Isopar ${ }^{\circledR} \mathrm{L}$ at $36{ }^{\circ} \mathrm{C}$ versus that at $21^{\circ} \mathrm{C}$. This is consistent with previous subtraction proving that the subtraction procedure did not introduce any impurities to the final result and no interaction peaks can be seen. 


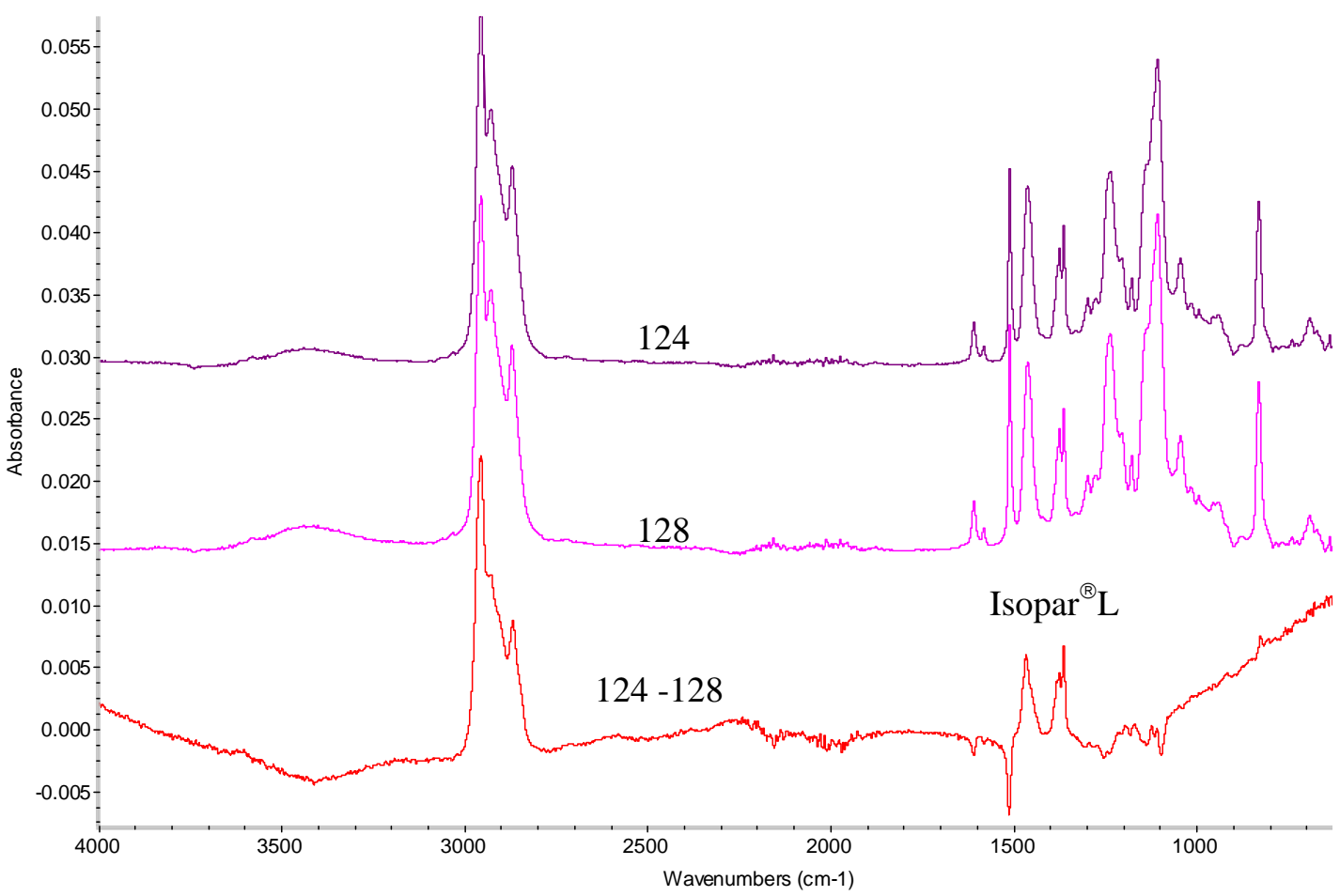

Fig. 4. The effect of temperature on the FTIR spectra of CSSX after contacting PPS fibers

\section{Exposed Nonwoven Fiber Shaped Analysis}

The PPS fibers from select samples in Table 2 (and another sample such as 128 which was exposed to baseline CSSX) were analyzed by FTIR. Fig. 5 shows the FTIR spectra of these fibers along with the spectrum of Cs-7SB and that of unexposed PPS for comparison. As can be seen from Fig. 5, the PPS fibers have excess Cs-7SB on their surfaces (typical of dried solvent with Isopar ${ }^{\circledR} \mathrm{L}$ evaporation). The presence of Cs-7SB makes it difficult to identify any residual component on the PPS surface (or changes to the Cs-7SB surface). The spectrum of Cs-7SB and of unexposed PPS was subtracted from each spectrum in Fig. 5. Fig. 6 shows the residual spectra from the subtraction process. As can be seen in Fig. 6, the PPS fibers lost $\mathrm{CH}_{2}$ groups and gained $\mathrm{CH}_{3}$ groups (along with some carbonyl groups). This feature may be residual hydrocarbon that remained in the PPS during manufacturing that may be released during exposure to NGS. The methane-carbonyl groups may be explained by the fact that fibers may have collected oxidized organic from the air. We do not see a build-up of $\operatorname{LIX}^{\circledR} 79$ in these fibers.

The remaining peaks, especially around 1600 to $1500 \mathrm{~cm}^{-1}$, are uncompensated peaks that remained after subtraction due to possible refractive index effects (i.e. from the preferential sorption of Modifier on PPS that may unevenly affects the baseline) from having a multilayer on the PPS fibers. The possible refractive index is due preferential sorption of Modifier on PPS fibers.

Magnified optical images of the PPS fibers were obtained before and after exposure to NGS to determine any perceptible changes to the fibers diameter. Fig. 7 shows the histogram obtained by measuring the fiber's diameters before and after exposure to NGS. The histogram data, as well as, visual inspection clearly shows that exposure to NGS had no impact on the physical dimensions of the PPS fibers. 


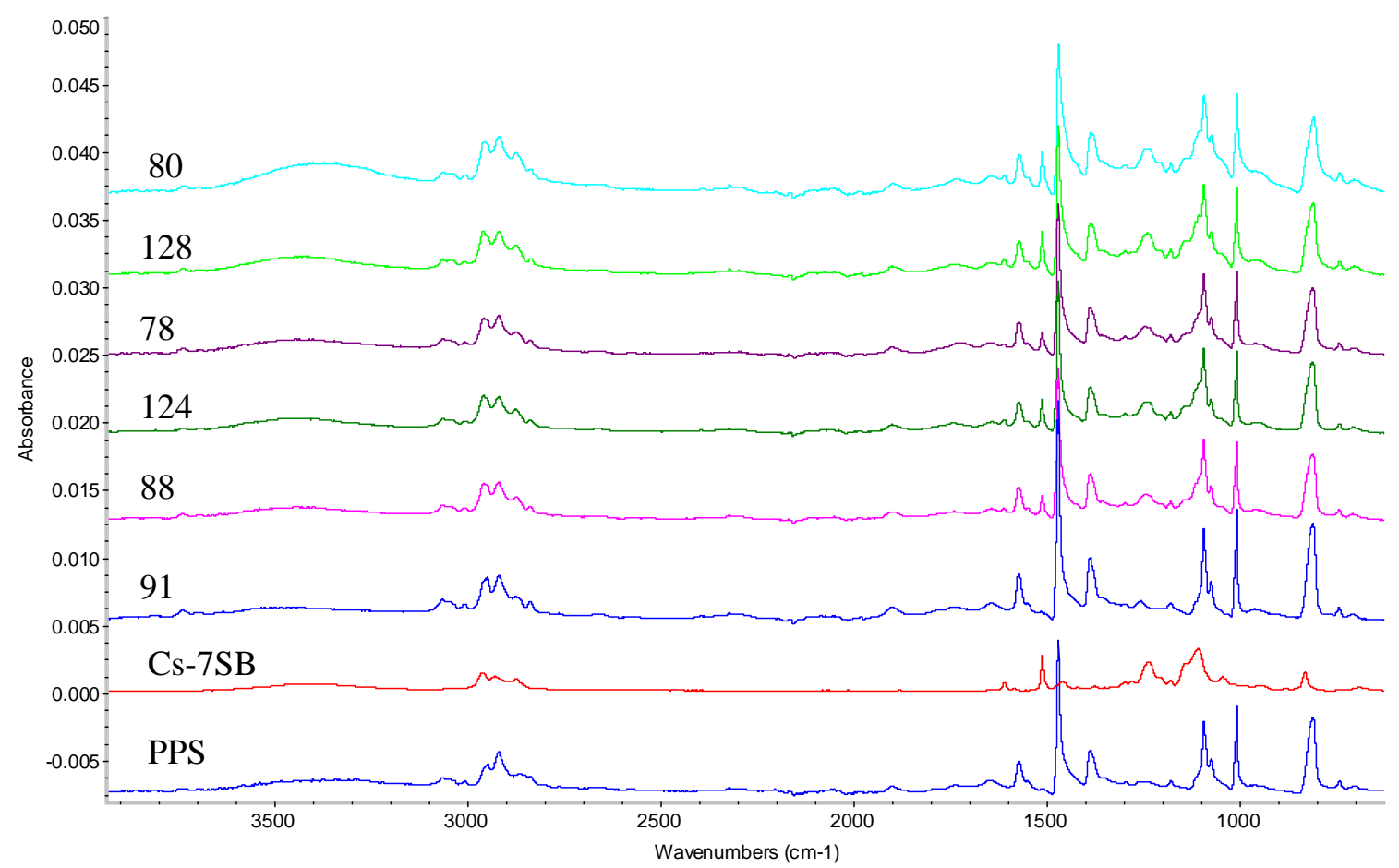

Fig. 5. The FTIR spectra of PPS after contacting Table 2 solvent samples at 21 and $36{ }^{\circ} \mathrm{C}$

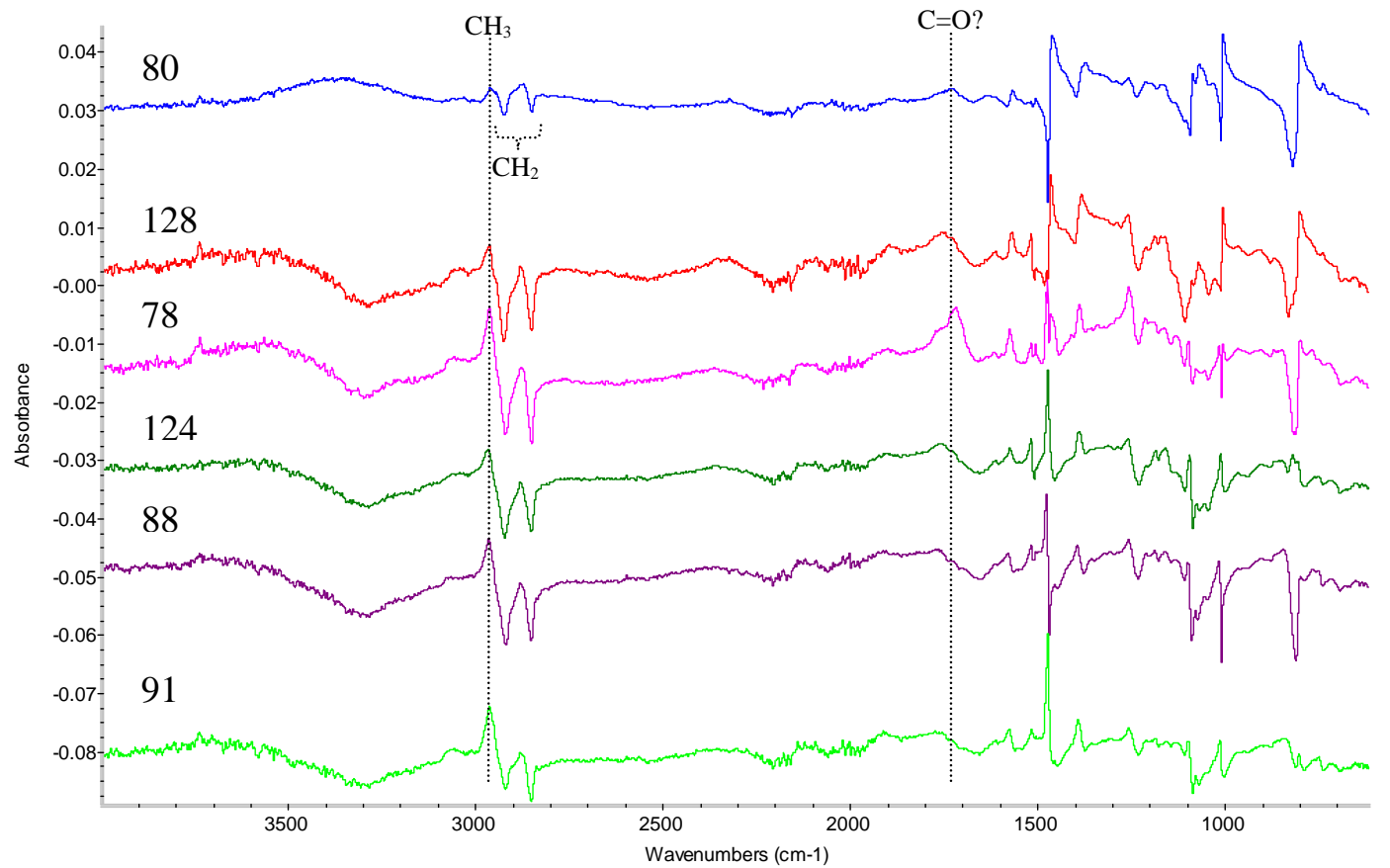

Fig. 6. Interaction spectrum of the spectra in Fig. 4 after subtracting the spectrum of Cs-7SB and PPS. 


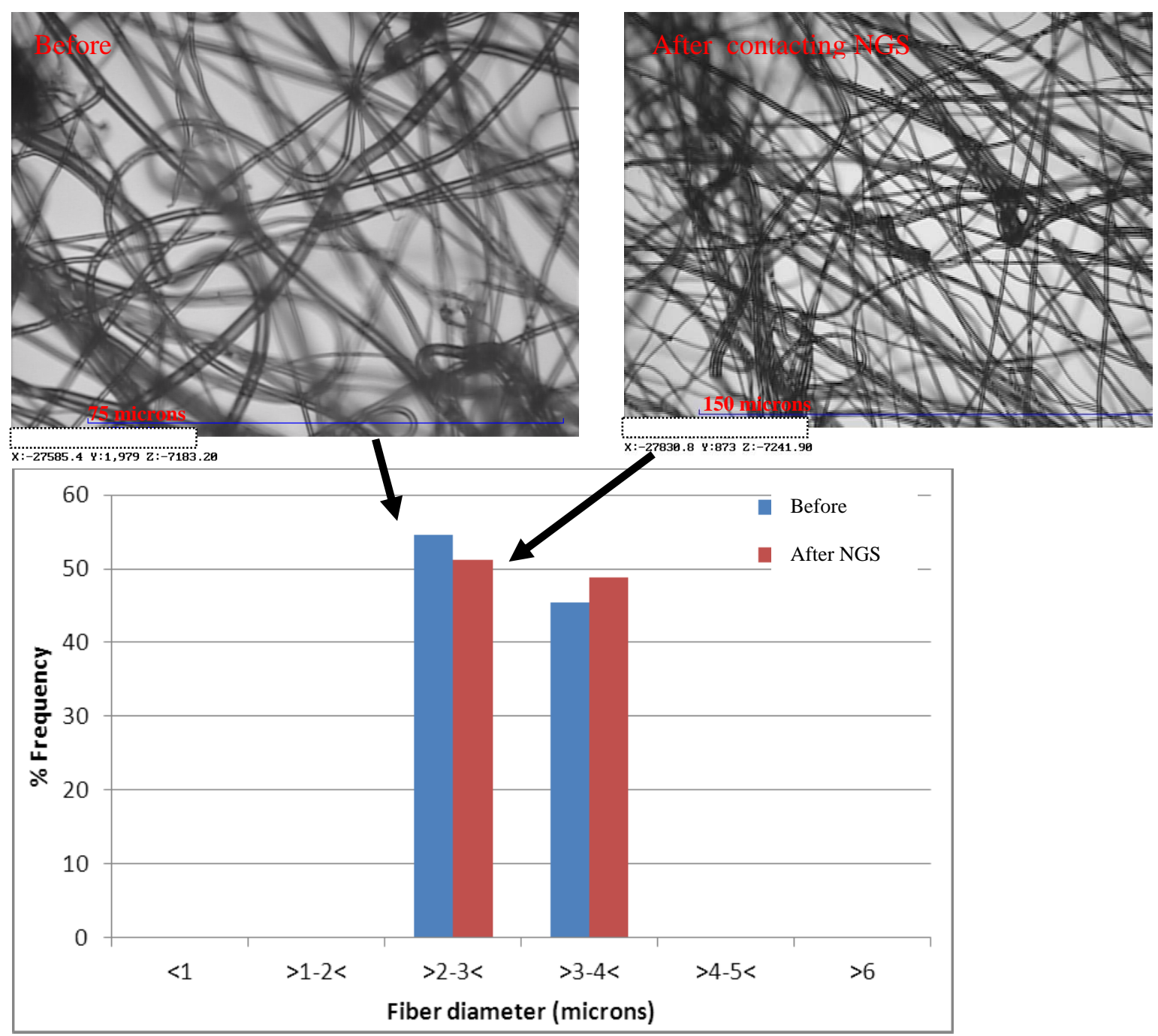

Figure 7. The Ryton fiber diameter before and after exposure to NGS for three months. The scale on the left figure should read 75 microns

\subsection{Conclusions}

PPS is remarkably stable in the presence of the next generation solvent. Testing showed no indication of swelling or significant leaching. Preferential sorption of the Modifier on PPS was observed but the same behavior occurs with the baseline solvent. Therefore, PPS coalescers exposed, to NGS, are expected to perform comparably to those in contact with the baseline solvent. Exposure to NGS had no effect on the physical dimensions of the PPS fibers. 


\subsection{References}

1 J. T. Edmonds and H. W. Hill, "U.S. Patent 3354129” 1967.

2 E. T. Suchida, F. Suzuki, E. Shouji, and K. Yamamoto, "Synthesis of PPS by oxidative $\mathrm{O}_{2}$ oxidative polymerization of methyl phenyl sulfide,” Macromolecules (1994), 27, 1057-1060.

${ }^{3}$ J. E. Spruiell and C. E. Janke, "A review of the measurement and development of crystallinity and its relation to properties in neat Polyphenyle sulfide and its fiber reinforced composite,” ORNL/TM-2002/304, August 2004.

${ }^{4}$ F. F. Fondeur, D. T. Herman, M. R. Poirier, and S. D. Fink, "The Chemical and Radiation Resistance of Polyphenylene Sulfide as Encounterd in the Modular Caustic-Side Solvent Extraction Process," SRNLSTI-2011-00390, June 30, 2011.

${ }^{5}$ N. J. Williams and B. A. Moyer, "Kinetics of Cesium Extraction and Stripping in the Next Generation Caustic Side Solvent Extraction (NG-CSSX) Process,” ORNL-LTR-NGCSSX-014, September, 2011.

${ }^{6}$ N. J. Williams, B. D. Roach, and B. A. Moyer, "Effect of Radiolytic and Thermal Treatment on the Performance of the Next-Generation Caustic-Side Solvent Extraction (NG-CSSX) Solvent," ORNL-LTRNGCSSX-017, September, 2011. 


\section{Distribution:}
A. B. Barnes, 999-W
S. D. Fink, 773-A
B. J. Giddings, 786-5A
C. C. Herman, 999-W
S. L. Marra, 773-A
F. M. Pennebaker, 773-42A
W. R. Wilmarth, 773-A
J. C. Griffin, 773-A
T. B. Peters, 773-42A
R. A. Pierce, 773-A
F. F. Fondeur, 773-A
R. T. McNew, 704-27S
J. E. Occhipinti, 704-S
J. W. Ray, 704-S
H. B. Shah, 766-H
D. C. Sherburne, 704-S
R. E. Edwards, 773-67A
M. W. Geeting, 241-152H
B. A. Gifford, 704-56H
B. A. Oard, $241-197 \mathrm{H}$
A. Samadi, 241-197H
S. McLeskey, 241-152H
D. J. Martin, 241-152H
E. J. Freed, 704-56H

W. Brasel, 992-2W

C. Conner, Parsons

R. D. Lentsch, Parsons

M. S. Brugh, Parsons

T. D. Burns, Parsons

A. N. Singer, Parsons

M. J. Thomas, Parsons

R. J. Schepens, Parsons

R. K. Leugemors, 992-5W

P. G. Suggs, 704-S

B. A. Moyer, ORNL

L. Delmau, ORNL

J. Birdwell, ORNL

P. Jackson, 703-46A 